\title{
Divergência genética em genótipos de feijão comum cultivados em Mato Grosso do Sul ${ }^{1}$
}

\author{
Agenor Martinho Correa ${ }^{2 *}$, Manoel Carlos Gonçalves ${ }^{3}$
}

\section{RESUMO}

O melhoramento do feijoeiro (Phaseolus vulgaris L.) baseia-se, principalmente, na hibridação de cultivares e linhagens, sendo importante o conhecimento da dissimilaridade entre os genitores para a obtenção de genótipos superiores. Este trabalho teve por objetivo promover o agrupamento de genótipos de feijoeiro comum, entre cultivares e linhagens, em função da dissimilaridade genética apresentada, indicar a contribuição relativa dos caracteres avaliados para a dissimilaridade genética e apontar as combinações híbridas mais promissoras para produzir recombinações superiores, utilizando-se de procedimentos multivariados. Desta forma, 13 genótipos de feijão comum, entre cultivares e linhagens avançadas, foram avaliados no ano agrícola 2005/2006, no período da "seca", na área experimental da Universidade Estadual do Mato Grosso do Sul, em Aquidauana. O experimento foi conduzido no delineamento de blocos casualizados, com três repetições, avaliando-se os caracteres: número de vagens por planta (NVP), número de grãos por vagem (NGV), massa de 100 grãos (MCG) e produtividade de grãos (PROD). Os genótipos foram reunidos em três grupos pelo método hierárquico do vizinho mais próximo e em cinco grupos pelas variáveis canônicas. O cultivar IAC Carioca Eté mostrou-se o mais dissimilar, podendo ser estrategicamente utilizado em hibridações artificiais dirigidas. O caráter "MCG" apresentou a maior contribuição relativa para a dissimilaridade genética total e as associações mais divergentes foram: "CNFv 8025 x IAC Carioca-Eté", "Rudá x IAC Carioca-Eté" e "CNF 7135 Bambuí x IAC Carioca-Eté".

Palavras-chave: Phaseolus vulgaris, análise multivariada, variabilidade genética.

\section{ABSTRACT}

\section{Genetic divergence in common bean genotypes grown in the State of Mato Grosso do Sul}

The common bean breeding is based, mainly on the hybridization of cultivars and lines, so it is important to know the dissimilarity among the parents to obtain superior genotypes. The objectives of this work were: to cluster the genotypes by multivariate techniques using hierarchical method (nearest neighbor) and the canonical variables; to point the relative contribution of the analyzed traits for genetic dissimilarity and to point out the most promising hybrid combinations to produce superior recombination using as dissimilarity measure the square of the Euclidean distance. Thus, thirteen bean genotypes (Phaseolus vulgaris L.), involving commercial varieties and advanced lines, were assessed at the experimental Campus at the Universidade Estadual de Mato Grosso do Sul - UEMS, in Aquidauana, Mato Grosso do Sul State, Brazil. The experiment was carried out in a randomized complete block design with three replications in the "dry" crop season, in the period 2005/2006. There were assessed the following traits: number of pods per plant (POD), number of seeds per pod (SEED), mass of 100 seeds (MHS) and grain yield (YD). The beans

\footnotetext{
Recebido para publicação em 28/10/2010 e aprovado em 17/02/2012

${ }^{1}$ Parte da Tese de Doutorado do primeiro autor apresentada à UFGD.

2 Engenheiro-Agrônomo, Doutor. Universidade Estadual de Mato Grosso do Sul (UEMS), Rodovia Aquidauana-CERA, Km 12, Zona Rural, CP 25, $79200-000$ Aquidauana, Mato Grosso do Sul, Brasil. agenor@uems.br*Autor para correspondência

${ }^{3}$ Engenheiro-Agrônomo, Doutor. Universidade Federal da Grande Dourados (UFGD), Rodovia Dourados - Itahum, Km 12, Cidade Universitária, 79804-970 Dourados, Mato Grosso do Sul, Brasil. ManoelGoncalves@ufgd.edu.br
} 
genotypes were clustered in three groups by nearest neighbor method and in five groups by canonical variables. The trait "MHS" had the highest relative contribution to total genetic dissimilarity. The cultivar IAC Carioca Eté was the most dissimilar and it can strategically be used in directed artificial hybridizations. The most divergent association were "CNFv 8025 x IAC Carioca-Eté", "Rudá x IAC Carioca-Eté" and "CNF 7135 Bambuí x IAC Carioca-Eté".

Key words: Phaseolus vulgaris L., multivariate analyses, genetic variability.

\section{INTRODUÇÃO}

Ao se iniciar um programa de melhoramento genético de plantas, um dos pontos mais críticos é a escolha dos genitores que participarão dos cruzamentos, para que se obtenha uma população de base genética ampla em que a seleção atuará.

Como o melhoramento do feijoeiro baseia-se, principalmente, na hibridação de cultivares e linhagens, gerando populações segregantes, em que se procede à seleção de linhagens superiores, torna-se importante o conhecimento da dissimilaridade entre os genitores.

Em vista disto, estudos sobre divergência genética, ou seja, diferenças nas frequências alélicas das populações são de grande importância em programas de melhoramento, pois permitem obter genitores adequados à obtenção de híbridos com maior efeito heterótico, que proporcionem maior segregação em recombinações, gerando população de base genética ampla que possibilite o aparecimento de transgressivos (Cruz \& Carneiro, 2003).

Falconer e Mackay (1996) esclarecem que a expectativa de que pais divergentes proporcionem bons híbridos decorre do fato de a heterose manifestada em híbridos ser função dos efeitos de dominância dos genes para o caráter em questão e do quadrado da diferença das frequências alélicas de seus genitores, além de efeitos epistáticos que geralmente são negligenciados.

Análises, que estimam a divergência genética, visando a orientar o melhorista quanto à escolha de genitores mais adequados aos cruzamentos, vêm sendo realizadas por diversos pesquisadores na cultura do feijoeiro (Benin et al., 2001; Rodrigues et al., 2002; Ferrão et al., 2002; Emygidio et al., 2003; Teixeira et al., 2004; Ribeiro et al., 2004; Abreu et al., 2004; Bonett, 2006; Coelho et al., 2007 e Rocha et al., 2009).

Os critérios para a escolha dos genitores normalmente restringem-se à análise de seu comportamento "per se" e nos resultados de cruzamentos dialélicos, com base nos quais se podem estimar a heterose e as capacidades específica e geral de combinação, manifestadas nos híbridos, com os quais se podem tirar inferências sobre a divergência genética das variedades. Tais alternativas apresentam dificuldades de ordem prática na realização dos cruzamentos, que aumentam quando um grande número de genitores é envolvido.
Outras medidas são as de natureza preditiva (Cruz \& Carneiro, 2003), que têm a vantagem de dispensar a obtenção prévia das combinações híbridas e de induzir os melhoristas a concentrarem seus esforços somente nas combinações mais contrastantes. Tais medidas baseiamse em diferenças morfológicas e fisiológicas dos genitores e empregam uma medida de dissimilaridade para avaliar a diversidade entre eles. Entre os métodos preditivos estão a distância euclidiana e a distância generalizada de Mahalonobis $\left(\mathrm{D}^{2}\right)$.

Outra forma de se estimar a divergência genética é por meio de técnicas de análise multivariada, ou de associações entre elas. Essas alternativas têm como finalidade básica a redução do número de variáveis e, consequentemente, a simplificação na obtenção das distâncias genéticas. Sua eficiência depende da quantidade de variação que essas novas variáveis explicam, em relação às variações existentes nos caracteres originais. Outra finalidade dessas alternativas é a identificação de grupos de indivíduos similares, após a estimação de uma matriz de dissimilaridade, de tal forma que exista homogeneidade dentro e heterogeneidade entre os grupos estabelecidos.

Este trabalho teve por objetivo promover o agrupamento de genótipos de feijoeiro comum, entre cultivares e linhagens, em função da dissimilaridade genética apresentada, indicar a contribuição relativa dos caracteres avaliados para a dissimilaridade genética e apontar as combinações híbridas mais promissoras para produzir recombinações superiores, utilizando-se de procedimentos multivariados.

\section{MATERIAL E MÉTODOS}

O experimento foi conduzido na Área Experimental da Universidade Estadual do Mato Grosso do Sul, Unidade Universitária de Aquidauana, no cultivo "da seca" do ano agrícola 2005/2006. O local onde o ensaio foi realizado está situado a $20^{\circ} 20^{\prime} 00^{\prime \prime}$ sul e $55^{\circ} 48^{\prime} 00^{\prime \prime}$ oeste, e altitude de 207 m. O clima da região é classificado como "Tropical Quente, Sub-Úmido" e o solo Argissolo Vermelho-Amarelo distroférrico, de textura arenosa e de média a alta fertilidade natural.

O delineamento experimental adotado foi o de blocos casualizados, com três repetições. Os genótipos avaliados foram provenientes do Banco Ativo de Germoplasma 
da EMBRAPA - CNPAF (Santo Antônio de Goiás, GO): cultivares Rudá, Aporé, Xamego, Pérola, Ouro Negro, Diamante Negro, IAPAR 14, ENGOPA 201- Ouro, IAC-Carioca Eté e as linhagens CNF 7135 Bambuí, CNF 4999-Rio Tibagi, CNF 4129 A 54 e CNF v. 8025. A unidade experimental constou de duas linhas de plantas com 1,50 m de comprimento, espaçadas de $0,50 \mathrm{~m}$ entre si.

A semeadura foi realizada no dia 20/04/2006, em sulcos abertos mecanicamente, distribuindo-se, no fundo, manualmente, o adubo químico na dose de $300 \mathrm{~kg} \mathrm{ha}^{-1} \mathrm{da}$ fórmula comercial 4-20-20, adotando-se a densidade de 15 sementes por metro linear.

Os tratos culturais constaram de duas capinas manuais, realizadas aos 15 e 30 dias após a emergência das plântulas e da adubação em cobertura, realizada com as plantas no estádio fenológico V4, distribuindo-se, manualmente, em filete contínuo ao lado das linhas das plantas, $60 \mathrm{~kg} \mathrm{ha}^{-1}$ de nitrogênio, empregando-se como fonte a ureia. Foi realizada uma aplicação do inseticida Deltamethrin, no estádio V3, visando ao controle de vaquinhas (crisomelídeos). A colheita, constando das operações de arranquio, amontoa e trilha, foi feita manualmente no período de 28/07 a 03/08/2006.

Foram avaliados os seguintes caracteres: número de vagens por planta (NVP), obtido pela média de vagens de oito plantas, tomadas aleatoriamente na parcela, por ocasião da colheita; número de grãos por vagem (NGV), obtido pela média de grãos por vagem nas oito plantas consideradas anteriormente, tendo sido avaliadas três vagens por planta; massa de 100 grãos (MCG), tomada, em grama, na pós-colheita; e produtividade de grãos (PROD), expressa em kg ha ${ }^{-1}$, obtidas considerando-se a área colhida e ajustando-se os dados para $13 \%$ de umidade.

Inicialmente, os dados obtidos para os caracteres foram submetidos à análise de variância, para se verificar a existência de variabilidade entre os genótipos. No modelo, assumiu-se o efeito de genótipo e de blocos como fixo e o de erros como aleatório, adotando-se o seguinte modelo estatístico:

$$
Y_{i j}=\mu+g_{i}+b_{j}+\varepsilon_{i j}
$$

em que: $Y_{i j}=$ valor observado do $i$-ésimo genótipo no $j$ ésimo bloco;

$\mu=$ média geral;

$g_{i}=$ efeito do genótipo $i$;

$b_{j}=$ efeito do bloco $j$;

$\varepsilon_{i j}=$ erro aleatório associado à observação $Y_{i j}$ sendo $\varepsilon_{i j} \diamond \mathrm{N}$ $\left(0 ; \sigma_{\varepsilon}^{2}\right)$.

Em seguida, realizou-se análise de variância multivariada, pela qual foram obtidos os arquivos de média e a matriz de variância e covariância residuais, destinadas a auxiliarem na interpretação e avaliação da variabilidade genética global entre os genótipos.

A divergência genética entre os tratamentos foi determinada pelas técnicas multivariadas, que se baseiam na análise de agrupamento e nas variáveis canônicas. $\mathrm{Na}$ análise de agrupamento, utilizou-se o quadrado da distância Euclidiana média (Cruz \& Carneiro, 2003) como medida de dissimilaridade e, na delimitação dos grupos, $\mathrm{o}$ método hierárquico do vizinho mais próximo (Johnson \& Wichern, 1992).

Quanto à análise por variáveis canônicas, a divergência genética foi evidenciada pela dispersão dos escores em gráfico bidimensional, com os eixos representados pelas primeiras variáveis canônicas que explicaram um mínimo de $80 \%$ da variação global entre os genótipos avaliados. Na obtenção das variáveis canônicas, adotaram-se os procedimentos preconizados por Cruz \& Regazzi (2004).

A identificação da importância dos descritores para a divergência genética foi feita com base na análise das variáveis canônicas, identificando os de menor importância como sendo aqueles cujos coeficientes de ponderação (autovetores) foram os de maior magnitude, em valor absoluto, nas últimas variáveis canônicas, pois as últimas variáveis são as que absorvem a menor parte da variância total (Hair et al., 2005). Pelo fato de os coeficientes serem influenciados pela escala de avaliação das características, procedeu-se a sua padronização.

Foi realizado também o estudo da importância relativa das características na predição da diversidade genética, por meio da participação dos componentes de $\mathrm{D}^{2}$, relativos a cada característica, no total da dissimilaridade observada, estimando-se, para tanto, a diversidade entre os genótipos também pela distância de Mahalanobis (Singh, 1981). As análises foram realizadas utilizando-se o aplicativo computacional em genética e estatística GENES (Cruz, 2006) e o aplicativo estatístico SPSS (Maroco, 2007).

\section{RESULTADOS E DISCUSSÃO}

Condições climáticas favoráveis durante todo ciclo da cultura propiciaram bom desempenho dos genótipos (Tabela 1). Foram observadas diferenças significativas ( $p$ $<0,01)$ entre genótipos para todos os caracteres avaliados, permitindo inferir sobre a existência de variabilidade genética (Tabela 2).

Os pares de genótipos mais próximos, determinados pelo quadrado da distância Euclidiana média (Tabela 3) foram: (Diamante Negro x IAPAR 14), (Xamego x CNF 4999 Rio Tibagi), (Ouro Negro x CNF 4999 Rio Tibagi), (Diamante Negro x Ouro Negro) e (IAPAR 14 x Xamego) (Tabela 3). Tais pares de genótipos, por apresentarem mesmo padrão de similaridade, não são recomendados para utilização em programas de melhoramento genético por hibridação, para que a variabilidade genética, indispensável em qualquer 
programa de melhoramento, não seja restrita, de modo a inviabilizar os ganhos a serem obtidos por seleção

Os pares mais divergentes foram: (CNFv 8025 x IAC Carioca-Eté), (Rudá x IAC Carioca-Eté) e (CNF 7135 Bambuí x IAC Carioca-Eté) (Tabela 3). Esses pares de genótipos, mostrando alta divergência, a princípio, deveriam ser os recomendados em cruzamentos, visando a maximizar a heterose nas progênies e a aumentar a possibilidade de ocorrência de segregantes nas gerações avançadas (Cruz et al., 2004).

Para Martins et al. (2002), a escolha dos genitores com base apenas em suas divergências, sem levar em consideração seus desempenhos, deve ser evitada. O mais apropriado, segundo os autores, é recomendar cruzamentos entre genitores divergentes que exibam, contudo, desempenho superior em relação às principais características agronômicas da cultura. Neste contexto, o cultivar IAC Carioca Eté, apesar de não ter tido um desempenho satisfatório, em relação ao grupo de genótipos avaliados (Tabela 1), a sua performance está acima do desempenho médio dos cultivares recomendados para cultivo no Estado, não devendo sofrer restrição quanto a este aspecto.

A contribuição relativa de cada caráter para a divergência genética é de grande importância para se identifi- car os caracteres de maior contribuição e, também, para auxiliar no descarte daqueles que contribuem pouco para a discriminação dos genótipos, reduzindo-se, dessa forma, mão de obra, tempo e custo despendidos na experimentação.

O caráter "MCG" foi o que mais contribuiu para a dissimilaridade genética, entre os genótipos testados, com participação de $65,83 \%$, seguido dos caracteres "NGV" (15,99\%), "PROD" (13,55\%) e "MVP" (4,69\%) (Tabela 4). Resultados semelhantes foram obtidos por Coimbra \& Carvalho (1999) e por Benin et al. (2001). Informação desta natureza é importante, por ser forte indicativo de que a seleção para este caráter deve ser priorizada em programas de melhoramento genético.

Os caracteres "PROD" e "NVP" não foram os mais importantes componentes primários da produção, na contribuição para a divergência genética entre os genótipos. Todavia, pelo fato de serem tais características as de maior importância no processo produtivo, não devem ser descartadas (Ferrão et al., 2002).

$\mathrm{O}$ agrupamento formado pelo método hierárquico do vizinho mais próximo, representado na Figura 1, estabelece que, primeiramente, é formado um grupo de genótipos similares e as distâncias dos demais são calculadas em

Tabela 1. Médias dos genótipos para quatro caracteres de feijão comum

\begin{tabular}{lcccc}
\hline Genótipos & NVP & NGV & MCG & PROD \\
\hline Rudá & $47,37 \mathrm{a}$ & $5,90 \mathrm{a}$ & $25,10 \mathrm{c}$ & $3174,80 \mathrm{a}$ \\
Aporé & $34,97 \mathrm{a}$ & $5,33 \mathrm{~b}$ & $29,03 \mathrm{a}$ & $2872,13 \mathrm{a}$ \\
Xamego & $39,03 \mathrm{a}$ & $6,17 \mathrm{a}$ & $21,10 \mathrm{e}$ & $2393,03 \mathrm{~b}$ \\
Pérola & $26,67 \mathrm{a}$ & $5,17 \mathrm{~b}$ & $30,10 \mathrm{a}$ & $2084,23 \mathrm{~b}$ \\
Ouro Negro & $34,10 \mathrm{a}$ & $4,80 \mathrm{~b}$ & $30,00 \mathrm{a}$ & $2251,86 \mathrm{~b}$ \\
Diamante Negro & $34,40 \mathrm{a}$ & $5,87 \mathrm{a}$ & $28,43 \mathrm{~b}$ & $2141,63 \mathrm{~b}$ \\
IAPAR 14 & $39,87 \mathrm{a}$ & $4,67 \mathrm{~b}$ & $27,26 \mathrm{~b}$ & $2167,60 \mathrm{~b}$ \\
EMGOPA-201 Ouro & $29,10 \mathrm{a}$ & $5,57 \mathrm{a}$ & $25,66 \mathrm{c}$ & $2446,70 \mathrm{~b}$ \\
IAC Carioca Eté & $33,20 \mathrm{a}$ & $5,00 \mathrm{~b}$ & $24,86 \mathrm{c}$ & $1725,50 \mathrm{~b}$ \\
Bambuí & $36,90 \mathrm{a}$ & $5,83 \mathrm{a}$ & $26,93 \mathrm{~b}$ & $2972,26 \mathrm{a}$ \\
CNF 4999 Rio Tibagi & $49,96 \mathrm{a}$ & $6,13 \mathrm{a}$ & $20,30 \mathrm{e}$ & $2360,26 \mathrm{~b}$ \\
CNF4129 A 54 & $39,70 \mathrm{a}$ & $5,56 \mathrm{a}$ & $23,70 \mathrm{~d}$ & $3048,27 \mathrm{a}$ \\
CNFv 8025 & $40,73 \mathrm{a}$ & $6,33 \mathrm{a}$ & $23,53 \mathrm{~d}$ & $3284,56 \mathrm{a}$ \\
\hline
\end{tabular}

$\mathrm{NVP}$ = número de vagens por planta; NGV = número de grãos por vagens; $\mathrm{MCG}=$ massa de 100 grãos; $\mathrm{PROD}=$ produtividade de grãos em $\mathrm{kg} \mathrm{ha}^{-1}$

Médias seguidas da mesma letra na coluna não diferem entre si pelo teste de agrupamento de Scott-Knott a 5\% de probabilidade.

Tabela 2. Análise de variância para quatro caracteres de feijão comum

\begin{tabular}{lcccc}
\hline \multirow{2}{*}{ F. V. } & \multicolumn{4}{c}{ Quadrados Médios } \\
\cline { 2 - 5 } & NVP & NGV & MCG & PROD \\
\hline Bloco & 33,98 & 0,12 & 0,22 & 128841,09 \\
Genótipo & $127,55^{* *}$ & $0,86^{* *}$ & $30,05^{* *}$ & $706359,60^{* *}$ \\
Resíduo & 41,54 & 0,18 & 0,88 & 66405,02 \\
Média & 37,38 & 5,56 & 25,85 & 2520,50 \\
\hline CV $(\%)$ & 17,24 & 7,72 & 3,63 & 10,17 \\
\hline
\end{tabular}

NVP = número de vagens por planta; NGV = número de grãos por vagens; $\mathrm{MCG}=$ massa de 100 grãos; PROD = produtividade de grãos em $\mathrm{kg} \mathrm{ha}^{-1} ;^{(* *)}=$ significativo a $1 \%$ de probabilidade pelo teste $\mathrm{F}$. 


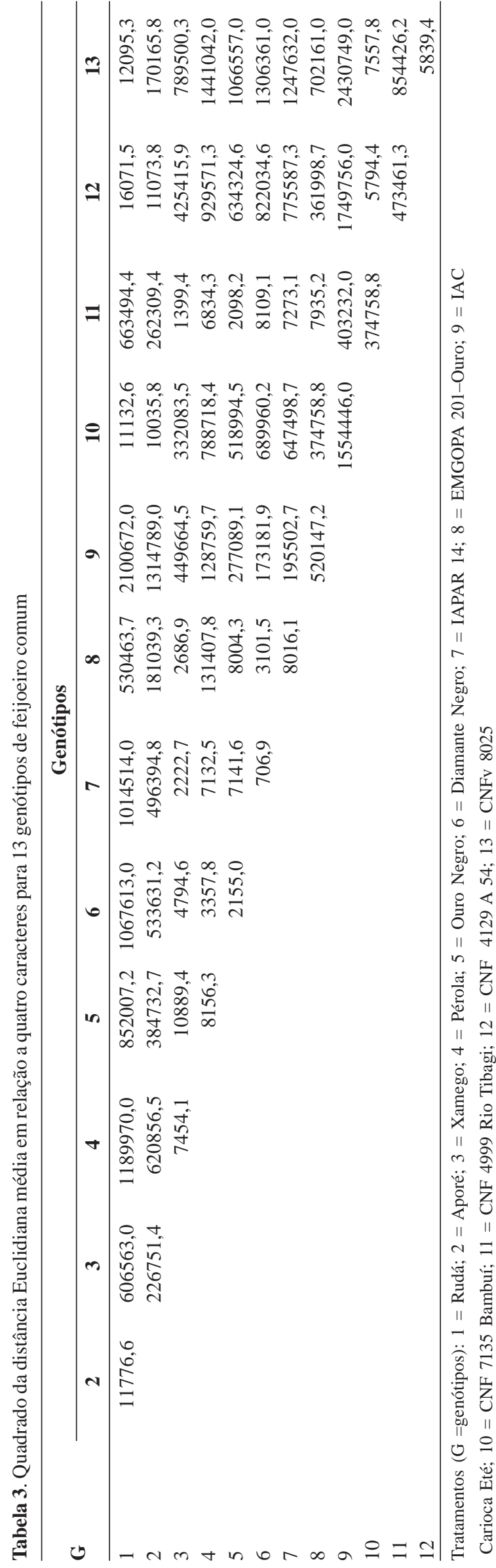

relação aos grupos formados (Cruz et al., 2004). Por esta técnica, os genótipos Diamante Negro e IAPAR 14; Xamego e CNF 4999 Rio Tibagi; Ouro Negro e CNF 4999 Rio Tibagi; Diamante Negro e Ouro Negro e; IAPAR 14 e Xamego são os mais similares, enquanto o IAC Carioca Eté é o que apresenta maior dissimilaridade em relação aos demais genótipos.

A posição de corte foi estabelecida pelo método do cálculo da raiz quadrada da distância euclidiana $\left(\mathrm{r}^{2}=0,92\right.$, $\mathrm{p}<0,01$ ) (Maroco, 2007), o que permitiu identificar a formação de três grupos de genótipos: grupo 1, formado pelos genótipos Rudá, CNFv 8025, Aporé, CNF 7135 Bambuí e CNF 4129A 54; grupo 2: Xamego, EMGOPA 201Ouro, CNF 4999 Rio Tibagi, Pérola, Ouro Negro, Diamante Negro e IAPAR 14 e um terceiro grupo, constituído apenas pelo genótipo IAC Carioca-Eté (Figura 1).

As estimativas dos autovalores (variâncias), das variâncias percentuais e das variâncias acumuladas das variáveis canônicas, relativas aos 13 genótipos de feijoeiro, podem ser visualizadas na Tabela 5 .

Observa-se que as duas primeiras variáveis canônicas explicam mais de $80 \%$ da variação total contida no conjunto de dados originais $(97,94 \%$ da variância total acumulada). A viabilidade da utilização da técnica das variáveis canônicas está restrita à concentração da variabilidade disponível entre as primeiras variáveis, a qual é referenciada por Cruz et al. (2004) como acima de $80 \%$.

Desta forma, as duas primeiras variáveis canônicas explicam satisfatoriamente a variabilidade manifestada entre os genótipos avaliados, permitindo interpretar o fenômeno, com considerável simplificação, por meio de um gráfico de dispersão bidimensional dos escores obtidos, conforme Figura 2.

O resultado gráfico dos escores das variáveis canônicas (Figura 2) foi discordante do agrupamento hierárquico do vizinho mais próximo (Figura 1), não apenas quanto ao número de grupos estabelecidos, mas, também, quanto aos genótipos constituintes dos grupos.

A inspeção visual dos escores no gráfico bidimensional (Figura 2) permitiu dividir os 13 genótipos em cinco grupos assim constituídos: grupo 1 , (genótipos 5 e 4 , respectivamente, Ouro Negro e Pérola); grupo 2, (genótipos 6 e 7, respectivamente, Diamante Negro e IAPAR 14); grupo 3, (genótipos 1 e 12, respectivamente, Rudá e CNF4129 A 54), grupo 4 (genótipos 11 e 3, respectivamente, CNF 4999 Rio Tibagi e Xamego) e grupo 5, ( genótipos 10 e 8, respectivamente, CNF 7135 Bambuí e ENGOPA 201 Ouro), permanecendo isolados os genótipos 2,9 e 13, respectivamente, Aporé, IAC Carioca Eté e CNFv 8025.

É importante mencionar que Xavier (1996) considera um tanto questionável a avaliação da divergência em análise gráfica, com o consequente estabelecimento de grupos de similaridade, por ser este proces- 
so bastante subjetivo, baseado em simples inspeção visual da dispersão.

A contribuição dos caracteres para a dissimilaridade genética, estimada empregando-se coeficientes de ponderação associados às variáveis canônicas (Tabela 6), apresentou boa concordância com a estimada pela estimativa S.j' de Singh (Tabela 4), indicando também, o cará- ter "MCG" como sendo aquele que mais contribuiu para a dissimilaridade entre os genótipos, o que ratifica a sua importância num programa de melhoramento para seleção de genótipos e corrobora resultados obtidos por outros pesquisadores já citados. O caráter "NVP", assim como na estimativa S.j', foi o que menos contribuiu para a dissimilaridade entre os genótipos.

Análise de Agrupamento Hierárquico

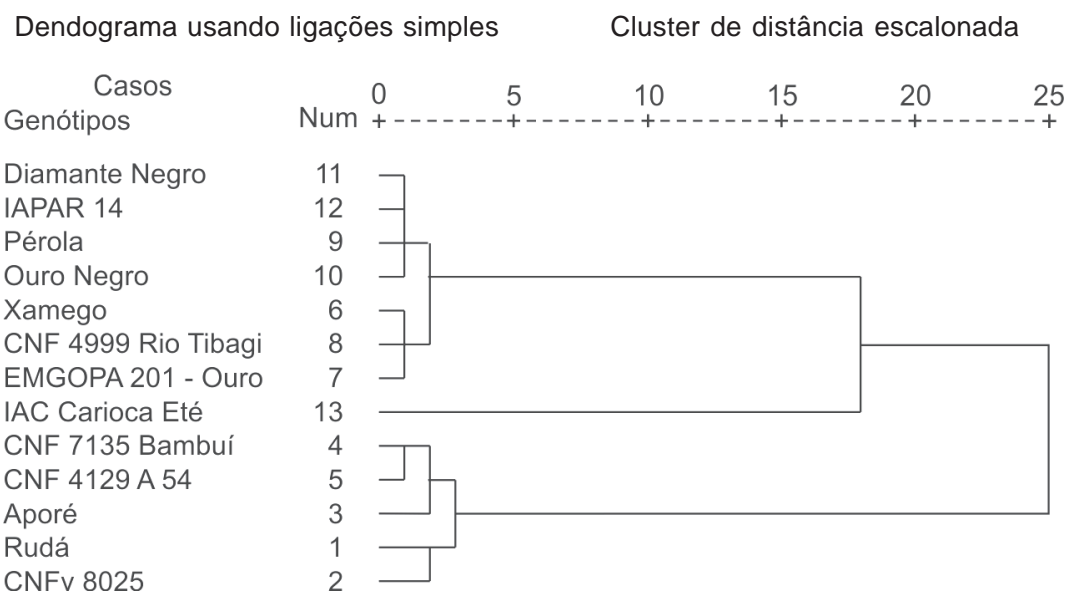

Figura 1. Dendrograma representativo da dissimilaridade genética entre os 13 genótipos estudados, obtidos pela técnica do vizinho mais próximo, utilizando o quadrado da distância Euclidiana média.

Tabela 4. Contribuição relativa de cada caráter para a dissimilaridade genética (S.j’) em 13 genótipos de feijoeiro comum

\begin{tabular}{lccc}
\hline Caráter & S.j & \% & \% acumulada \\
\hline NVP & 351,30 & 4,63 & 4,63 \\
NGV & 1213,92 & 15,99 & 20,62 \\
MCG & 4998,18 & 65,83 & 86,45 \\
PROD & 1029,24 & 13,55 & 100,00 \\
\hline
\end{tabular}

$\mathrm{NVP}=$ número de vagens por planta; NGV = número de grãos por vagens; $\mathrm{MCG}=$ massa de 100 grãos; PROD = produtividade de grãos em $\mathrm{kg} \mathrm{ha}^{-1}$;

Tabela 5. Variáveis (autovalores), variâncias percentuais e variâncias acumuladas das variáveis canônicas, para estimação da dissimilaridade entre 13 genótipos de feijoeiro comum

\begin{tabular}{lccc}
\hline VC & $\boldsymbol{\lambda} \boldsymbol{I}$ & $\boldsymbol{\lambda} \boldsymbol{I}(\boldsymbol{\%})$ & $\boldsymbol{\%}$ acumulada \\
\hline VC 1 & 44,683 & 91,808 & 91,808 \\
VC 2 & 2,985 & 6,135 & 97,943 \\
VC 3 & 0,721 & 1,481 & 99,424 \\
VC 4 & 0,279 & 0,575 & 100,000 \\
\hline
\end{tabular}

$\mathrm{VC}=$ variáveis canônicas; $\lambda I=$ variância; \% acumulada $=\%$ da variância acumulada.

Tabela 6. Coeficientes de ponderação (autovetores) associados às variáveis canônicas das características avaliadas

\begin{tabular}{lllll}
\hline VC & NVP & NGV & MCG & PROD \\
\hline VC 1 & $-0,351$ & $-1,077$ & 1,472 & $-0,669$ \\
VC 2 & 0,176 & $-0,065$ & 0,270 & 0,886 \\
VC 3 & $-0,747$ & 0,738 & 0,046 & $-0,059$ \\
VC 4 & 0,616 & 0,485 & 0,222 & $-0,258$ \\
\hline
\end{tabular}

$\mathrm{NVP}=$ número de vagens por planta; NGV = número de grãos por vagens; $\mathrm{MCG}=$ massa de 100 grãos; PROD = produtividade de grãos em $\mathrm{kg} \mathrm{ha}^{-1} ; \mathrm{VC}=$ variáveis canônicas 


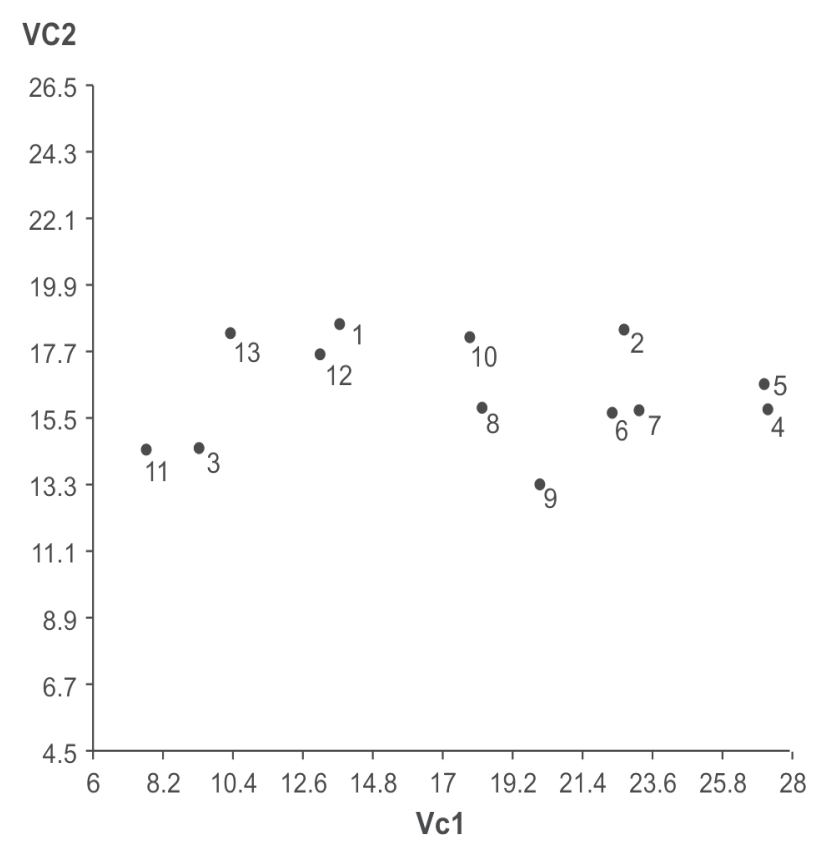

Figura 2. Dispersão gráfica dos escores dos 13 genótipos de feijoeiro comum, utilizando-se as duas primeiras variáveis canônicas.

1 = Rudá; 2 = Aporé; 3 = Xamego; 4 = Pérola; 5 = Ouro Negro; $6=$ Diamante Negro; 7 = IAPAR 14; 8 = EMGOPA 201-Ouro; 9 = IAC Carioca Eté; 10 = CNF 7135 Bambuí; 11 = CNF 4999 Rio Tibagi; $12=$ CNF 4129 A 54; $13=$ CNFv 8025.

\section{CONCLUSÕES}

O caráter "MCG" é o que mais contribuiu para a dissimilaridade total entre os genótipos e "NVP" o que menos contribuiu.

As técnicas de análise multivariada utilizadas reuniram os genótipos em grupos distintos.

Híbridos com maior efeito heterótico serão obtidos dos cruzamentos entre os genótipos "CNFv 8025 x IAC Carioca Eté”, "Rudá x IAC Carioca Eté” e "CNF 7135 Bambuí x IAC Carioca-Eté".

\section{AGRADECIMENTOS}

Os autores agradecem à Fundação de Apoio ao Desenvolvimento de Ensino Ciência e Tecnologia de Mato Grosso do Sul (FUNDECT), pela concessão de bolsa ao primeiro autor e, à EMBRAPA - CNPAF, pela oportunidade de realização do ensaio, pelo apoio e por autorizar a publicação dos resultados obtidos.

\section{REFERÊNCIAS}

Abreu FB, Leal NR, Rodrigues R, Amaral Júnior AT \& Silva DJH (2004) Divergência genética entre acessos de feijão-de-vagem de hábito de crescimento indeterminado. Horticultura Brasileira, 22: 547-552.
Benin G, Carvalho FIF, Assmann I C, Cigolini PJC, Marchioro VS, Lorencetti C \& Silva SAS (2001) Dissimilaridade genética em feijão (Phaseolus vulgaris L.) com grão tipo carioca. Pesquisa Agropecuária Gaúcha, 7: 237-244.

Bonett LP, Gonçalves-Vidigal MC, Schuelter AR, Vidigal Filho OS, Gonela A \& Lacanallo GF (2006) Divergência genética em feijoeiro comum coletado no Estado do Paraná, Brasil. Semina: Ciência Agrárias, 27: 547-560.

Coelho GMM, Coimbra JLM, Souza CA \& Bogo A, Guidolim AF (2007) Diversidade genética em acessos de feijão (Phaseolus vulgaris L.). Ciência Rural, 37: 1241-1247.

Coimbra JLM \& Carvalho FIF (1999) Divergência genética em genótipos de feijão preto (Phaseolus vulgaris L.) predita através de variáveis quantitativas. Revista Científica Rural, 4: 4753.

Cruz CD (2006) Programa GENES: Biometria. Viçosa, Editora UFV. 382 p.

Cruz CD \& Carneiro PCS (2003) Modelos biométricos aplicados ao melhoramento genético. Viçosa, Editora UFV. 585 p.

Cruz CD, Regazzi AJ, Carneiro PCS (2004) Modelos biométricos aplicados ao melhoramento genético. Viçosa, Editora UFV. $585 \mathrm{p}$.

Emygidio BM, Antunes IF, Nedel JL \& Choer E (2003) Diversidade genética em cultivares locais e comerciais de feijão baseada em marcadores RAPD. Pesquisa Agropecuária Brasileira, 38: 1165-1171.

Falconer DS \& Mackay TF (1996) Introduction to quantitative genetics. $4^{\mathrm{a}}$ ed. Londres, Longman Group. 464 p.

Ferrão MAG, Vieira C, Cruz CD \& Cardoso AA (2002) Divergência genética em feijoeiro em condições de inverno tropical. Pesquisa Agropecuária Brasileira, 7: 1089-1098.

Hair IF, Anderson RF, Tathan RI \& Black WC (2005) Análise multivariada de dados. $5^{\mathrm{a}}$ ed. Porto Alegre, Bookman. 593 p.

Johnson RA \& Wichern DW (1992) Applied multivariate statistical analysis. New Jersey, Englewood Cliffs. 642 p.

Maroco J (2007) Análise estatística com a utilização SPSS. Lisboa, Silabo. 822 p.

Martins IS, Pires IE \& Oliveira MC (2002) Divergência genética em progênies de uma população de Eucalyptus camaldulenses DEHNH. Floresta e Ambiente, 9: 81-89.

Ribeiro ND, Hoffman Júnior L \& Possebon SB (2004) Variabilidade genética para ciclo em feijão dos grupos preto e carioca. Revista Brasileira de Agrociência, 10: 19-29.

Rocha FR, Banli LD, Garcia SH, Modena R, Coimbra JLM, Guidolin AF \& Bertoloto JG (2009) Seleção em populações mutantes de feijão (Phaseolus vulgaris L.) para caracteres adaptativos. Revista Biotemas, 22: 19-27.

Rodrigues LS, Antunes IF, Teixeira MG \& Silva, JB (2002) Divergência genética entre cultivares locais e cultivares melhoradas de feijão. Pesquisa Agropecuária Brasileira, 37: 1275-1284.

Singh D (1981) The relative importance of characters affecting genetics divergence. The Indian Journal of Genetics \& Plant Breeding, 41: 237-245.

Teixeira AB, Amaral Júnior AT, Rodrigues R, Pereira TNS \& Bressan-Smith RE (2004) Genetic divergence in snap-bean (Phaseolus vulgaris L.) evaluated by different methodologies. Crop Breeding and Applied Biotechnology, 4: 57-62.

Xavier A (1996) Aplicação da análise multivariada da Divergência genética no melhoramento de Eucalyptus spp. Tese de Doutorado. Universidade Federal de Viçosa, Viçosa, 129 p. 